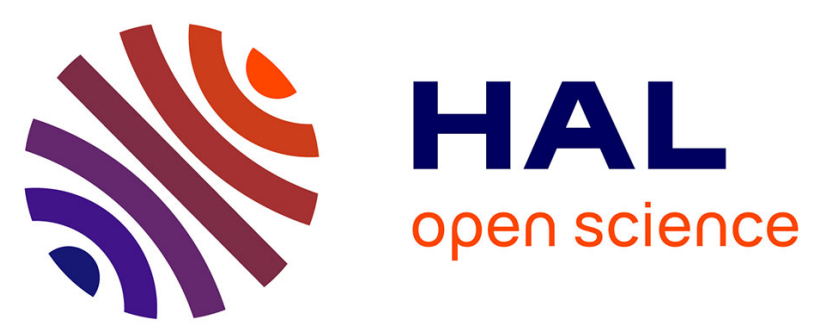

\title{
Predictors of respiratory sickness absence: an international population-based study.
}

Jeong-Lim Kim, Paul D Blanc, Simona Villani, Mario Olivieri, Isabel Urrutia, Marc van Sprundel, Torgeir Storaas, Nicole Le Moual, Jan-Paul Zock, Kjell Torén

\section{To cite this version:}

Jeong-Lim Kim, Paul D Blanc, Simona Villani, Mario Olivieri, Isabel Urrutia, et al.. Predictors of respiratory sickness absence: an international population-based study.. American Journal of Industrial Medicine, 2013, 56 (5), pp.541-9. 10.1002/ajim.22178 . inserm-01324108

\section{HAL Id: inserm-01324108 https://www.hal.inserm.fr/inserm-01324108}

Submitted on 31 May 2016

HAL is a multi-disciplinary open access archive for the deposit and dissemination of scientific research documents, whether they are published or not. The documents may come from teaching and research institutions in France or abroad, or from public or private research centers.
L'archive ouverte pluridisciplinaire HAL, est destinée au dépôt et à la diffusion de documents scientifiques de niveau recherche, publiés ou non, émanant des établissements d'enseignement et de recherche français ou étrangers, des laboratoires publics ou privés. 


\section{Predictors of respiratory sickness absence: an international population-based study}

Jeong-Lim Kim, PhD, ${ }^{1}$ Paul D. Blanc, MD, MSPH, ${ }^{2}$ Simona Villani, PhD, ${ }^{3}$ Mario Oliveri, $\mathrm{MD},{ }^{4}$ Isabel Urrutia, MD, $\mathrm{PhD}^{5}$ Marc van Sprundel, MD, $\mathrm{PhD},{ }^{6}$ Torgeir Storaas, $\mathrm{MD}, \mathrm{PhD},{ }^{7,8}$ Nicole Le Moual, PhD, ${ }^{9,10}$ Jan-Paul Zock, PhD ${ }^{11,12,13}$ Kjell Torén, MD, PhD ${ }^{1}$

${ }^{1}$ Section of Occupational and Environmental Medicine, Institute of Medicine, Sahlgrenska Academy at University of Gothenburg, Gothenburg, Sweden; ${ }^{2}$ Division of Occupational and Environmental Medicine, Dept. of Medicine, University of California San Francisco, San Francisco, California, USA; ${ }^{3}$ Section of Medical Statistics and Epidemiology, Dept. of Health Sciences, University of Pavia, Italy; ${ }^{4}$ Unit of Occupational Medicine, University Hospital of Verona, University of Verona, Italy; ${ }^{5}$ Pneumology Department, Galdakao Hospital, Galdakao, Bizkaia, Spain; ${ }^{6}$ Dept. of Epidemiology and Social Medicine, University of Antwerp, Antwerp, Belgium; ${ }^{7}$ Dept. of Otolaryngology, Head \& Neck Surgery, Haukeland University Hospital, Bergen, Norway; ${ }^{8}$ Section of Clinical Allergy, Dept. of Occupational Medicine, Haukeland University Hospital, Bergen, Norway; ${ }^{9}$ Inserm, CESP Centre for Research in Epidemiology and Population Health, U1018, Respiratory and Environmental Epidemiology Team, Villejuif, France; ${ }^{10}$ Université Paris Sud 11, UMRS 1018, Villejuif, France; ${ }^{11}$ Centre for Research in Environmental Epidemiology (CREAL), Barcelona, Spain; ${ }^{12}$ Hospital del Mar Research Institute (IMIM), Barcelona, Spain; ${ }^{13}$ CIBER Epidemiología y Salud Pública, Spain. 
Correspondence to: Dr. Jeong-Lim Kim, Section of Occupational and Environmental

Medicine, Sahlgrenska Academy at University of Gothenburg, Box 414, S-405 30

Gothenburg, Sweden. Fax: +4631409728. E-mail: Jeong-Lim.Kim@amm.gu.se

Competing interests: None declared

Running head: Predictors of respiratory sickness absence

Word count (abstract and text only): 3891

Keywords: Asthma, job termination, rhinitis, wheeze, work disability, work exposure 


\begin{abstract}
Background: Respiratory tract-related occupational disability is common among adults of working age. We examined occupational vapors, gas, dust, or fume (VGDF) exposure as a predictor of disability, based on respiratory sickness absence among the actively employed, at an early point at which prevention may be most relevant.

Methods: Currently employed European Community Respiratory Health Survey II participants $(n=6,988)$ were classified into three mutually exclusive, condition/symptombased categories: physician-diagnosed asthma, self-reported rhinitis, and wheeze/breathlessness $(n=4,772)$. Logistic regression analysis estimated the odds of respiratory sickness absence (past 12 months) by VGDF exposure.
\end{abstract}

Results: In the condition/symptom groups, 327 (6.9\%) reported respiratory sickness absence. Exposure to VGDF was associated with increased odds of respiratory sickness absence: asthma odds ratio [OR] 2.0 (95\% confidence interval [CI] 1.1-3.6), wheeze/breathlessness OR 2.2 (95\% CI 1.01-4.8); rhinitis OR 1.9 (95\% CI 1.02-3.4).

Conclusion: One in 15 currently employed with asthma, breathlessness or rhinitis reported respiratory sickness absence. VGDF exposure doubled the odds of respiratory sickness absence, suggesting a focus for disability prevention. 


\section{Introduction}

Occupational disability linked to respiratory conditions and their symptoms is common among adults of working age. Among those with asthma or asthma-like symptoms, the incidence of job change due to respiratory problems, a key measure of respiratory work disability, is 5.7/1,000 person-years [Toren et al., 2009]. Previous studies of the cohort we analyzed here have shown that asthma severity and occupational exposure to vapors, gases, dusts or fumes (VGDF) are important predictors for respiratory work disability when defined as job change due to breathing symptoms [Blanc et al., 2003; Toren et al., 2009; Murgia et al., 2011]. Such disability not only reflects poorer health status, but is also likely to negatively influence quality of life [Vandenplas et al., 2003].

However, job change (or complete work cessation) due to respiratory ill-health does not capture the experiences of employees who have reduced work ability but have not yet been forced by their problems to change their job or to cease working altogether. A recent study found that absenteeism is common within a working asthmatic population in Spain and that the severity of asthma was one of the important factors predicting such absenteeism [Gonzalez Barcala et al., 2011]. Moreover, there is evidence that respiratory-related work absences may be a harbinger of more serious disability.

A study of respiratory sickness found that blue collar relative to white collar jobs were at increased risk of absences and of taking longer to return to work [Alexopoulos and Burdorf 2001]. Another study found that among men respiratory illness work absence carried twice the risk of long-term disability of that due to musculoskeletally attributed absence, but did not explore the role of occupational exposures in this pathway [Koopmans et al., 2008].

Hence, it would be advantageous to identify respiratory work disability at an earlier phase as manifested by respiratory ill health specific work absences. It is particularly important to increase our understanding of the predictors of this early phase respiratory work disability, as this could provide knowledge that might guide early interventions.

The primary aim of this study was to investigate the frequency of and risk factors for respiratory sickness absence among a working population, in particular, the role that workplace exposures to vapors, gas, dust or fume (VGDF) might play in this process. A secondary study aim was to test risk models of respiratory sickness absence among different categories of respiratory tract conditions/symptoms. 


\section{Materials and Methods}

\section{Study design and study population}

The present study is an analysis of data from the European Community Respiratory Health Survey (ECRHS) II, a follow-up study cohort derived from a population-based, multinational survey of adults aged 20-44 years at original recruitment at 26 study centers in 11 European and two non-European countries. The study designs of ECRHS II and its baseline counterpart, ECRHS I, have been previously described in detail [European Respiratory Health Survey II Steering Committee 2002; Bedada et al., 2007; Burney et al., 1994]. In brief summary, the baseline study was performed in two stages, with each participant completing a screening questionnaire, and a randomly selected $20 \%$ subgroup of these respondents being invited for more extensive interviews and clinical testing [Burney et al., 1994]. In addition to this random subset of the screening questionnaire group, participants who reported respiratory symptoms at the screening stage and who were not already selected at random for the first group were considered eligible for participation in a "symptom-enriched" sub-group that was also invited to complete a supplemental questionnaire and participate in a clinical examination. Thus, a key feature of the ECHRS I is that symptomatic individuals could have been included in the extensive interview/clinical examination portion of the study either by random selection or because of their symptoms. The $20 \%$ random group was used to draw inferences about general population rates of symptoms and outcomes; the symptom-enriched group to provide the power to analyze associations with specific respiratory outcomes. All participants who underwent supplemental interviews and examinations (both the random 20\% subgroup and the symptom enriched sub-group) were eligible for re-contact for inclusion eight years later in the ECRHS II follow-up, in which $65 \%$ of the baseline subjects ultimately participated [Bedada et al., 2007].

For the present analysis, the study population was restricted to those fulfilling the following inclusion criteria: at follow-up interview, currently working and having been working for at least one year at the current workplace (year-long employment calculated by subtracting the start date of the job from either the end date of the job or the date of questionnaire completion) and no missing data for key variables (sex, smoking status, information on work exposure, days lost in the previous year attributed to respiratory illness, wheeze/breathlessness, rhinitis, asthma, and asthma symptom score in those subjects with asthma). Exclusions were due to: 2,369 not currently working or to providing no job 
description; 703 working duration less than 365 days;, 152 missing data on smoking status; 19 missing data on VGDF exposure; 423 missing data on wheeze/breathlessness; 21 missing data on asthma; 33 having asthma but no data on which to base their symptom scores; 63 missing data on rhinitis. After exclusions, the study population consisted of those drawn from both the original random $20 \%$ subset $(n=5,962)$ and the original symptom-enriched subset $(n=1,036)$. Details of the study population used in this analysis are presented in Figure 1.

\section{Questionnaire and definitions}

The ECRHS II questionnaire contained questions about respiratory illness regarding wheeze, breathlessness, physician-diagnosed asthma, and other respiratory tract problems (including rhinitis), as well as items ascertaining smoking habits, occupations, leaving any job due to respiratory symptoms, and sickness absence due to respiratory symptoms.

Asthma was defined as affirmative answers to both of the following questions: "Have you ever had asthma?" and "Was this confirmed by a doctor?"

Wheeze/Breathlessness was defined as positive answers to both of the questions "Have you had wheezing or whistling in your chest at any time in the last 12 months?" and "Have you had this wheezing or whistling when you did not have a cold?" or an affirmative answer to any of the following three questions: 1) attack of shortness of breath at rest in the last 12 months; 2) attack of shortness of breath while performing strenuous activity in the last 12 months; and 3) being woken up by an attack of shortness of breath in the last 12 months.

Rhinitis was defined as an affirmative answer to the question "Have you had a problem with sneezing or a runny or blocked nose without having a cold or flu in the last 12 months?”

For the current study analyses, the subjects were allocated to three mutually-exclusive condition/symptom-based groups: 1) Asthma - subjects with physician-diagnosed asthma as per the definition of asthma above; 2) Wheeze/breathlessness - subjects with wheeze or breathlessness but not physician-diagnosed asthma; 3) Rhinitis - subjects with self-reported rhinitis but neither physician-diagnosed asthma nor wheeze/breathlessness. In addition to these three categories, we also retained the original ECHRS random sample designation, which we refer to as the "random all-population sample." This group includes both individuals who had been symptomatic and those that had been asymptomatic at their baseline study inclusion. This category, which overlapped with many of the participants that otherwise 
fell into one of the three condition/symptom groups already noted above all, was retained so that respiratory work absence could be modeled in the general population.

The ECRHS II study was approved by institutional and regional ethics committees in all study centers, and all participants provided written informed consent.

\section{Respiratory sickness absence}

Self-reported work loss due to respiratory problems in the last 12 months was used as an outcome variable for respiratory sickness absence. The variable was queried as "How many days of work have you lost because of asthma, shortness of breath, or wheezing in the last 12 months?" Answers were dichotomized for statistical analysis ( $0=$ no days; $1=$ at least one day). For additional analyses, predictive models defining absence as more than three days of respiratory sickness absence were tested ( $0=$ up to 3 days; $1=$ more than 3 days of respiratory sickness absence). Finally, leaving any job that affected their breathing was also assessed.

\section{Explanatory variables}

Sex, age, smoking status (never smoker, ex-smoker, and current smoker), and current occupational exposure (none, low and high; see below for details) were examined as potential independent determinants of respiratory work disability. Occupations, including starting-year and stopping-year during the period of follow-up, were ascertained and responses coded according to the international Standard Classification of Occupations [International Labour Organization. 1991]. These codes were then linked to the ALOHA-job exposure matrix to classify the likelihood of VGDF exposure in each job as being of likelihood of exposure rated none, low or high for each of three classes of exposure; biological, inorganic dusts, and vapors and gases [Matheson et al., 2005; Sunyer et al., 2005; Toren et al., 2009]. The likelihood of any VGDF exposure was expressed by assigning priority to the highest exposure likelihood achieved in the job exposure matrix among the three allowable categories. For example, a low likelihood for biological dust but a high likelihood for exposure to gas or fumes would be assigned a "high" likelihood of any VGDF exposure; a low likelihood of exposure to gas and fume but none for the other categories would be assigned "low." Additional analyses were performed using models also including second hand tobacco smoke exposure at work during the last 12 months as a further exposure variable. 
For those with physician-diagnosed asthma, a continuous 5-point scale was constructed by summing positive answers to questions on the following five asthma-consistent symptoms in the last 12 months: wheeze, being woken by tightness in the chest, attack of shortness of breath while resting, attack of shortness of breath while performing strenuous activity; and being woken by an attack of shortness of breath. This technique has been previously used elsewhere based on ECRHS data [Sunyer et al., 2007; Toren et al., 2009].

\section{Statistical analysis}

Continuous variables are presented as the arithmetic mean with standard deviation (SD) or with min-max value; categorical variables as the frequency and percentage. For all variables, the reference was defined as the lowest value among the variables, following an ascending order. For statistical analysis, smoking was dichotomized $(0=$ never smoker; and $1=$ ex-smoker or current smoker) and the countries of ECRHS participating centers were categorized into four different regions, namely northern (referent), central, and southern European countries and one region for the UK, USA, and Australia.

To study associations between respiratory sickness absence and potential predictors, multiple logistic regression models were performed with mutual adjustments for potential confounding factors, including geographic region of the international study centers. Moreover, random intercept logistic regression models were carried out with inclusion of the same factors as in conventional logistic regression model but with geographic region included as a random effects variable. Each of the subgroups was separately modeled. Additional multiple logistic regression modeling included second hand smoke exposure at work to test its effect on risk estimates. Finally, stratification by sex and childhood asthma (onset before age 17 years) was carried out in order to evaluate whether the study results remained consistent within such strata.

In the multiple regression models, multicollinearity was tested to detect the effect of intercorrelation among explanatory variables by using variance inflation factor. Variance inflation factor values were below 1.5 in all the presented models, thus indicating no signs of serious multicollinearity requiring correction [Cody and Smith 2005].

Hosmer-Lemeshow goodness-of-fit statistics were used to assess the calibration of the models, and all models which met the criteria are presented either in text or in tables. The 
results of regression analyses are presented as odds ratios (OR) with 95\% confidence intervals (CI). OR for asthma symptoms score is expressed per point change in score. All statistical analyses were performed using version 9.2 of SAS for Windows (SAS Institute, Inc., Cary, $\mathrm{NC}, \mathrm{USA}$ ), applying two-tailed tests and a $5 \%$ level of significance.

\section{Results}

A total of 6,998 participants met the inclusion criteria for the current study, after exclusion of those missing data for key study factors (Figure 1). Of these, 1,047 were included in the condition/symptom group asthma, 1,648 in wheeze/breathlessness group (without asthma), and 2,077 in the rhinitis group (without either of the two preceding designations). There were 5,962 survey participants in the random all-population sample category (of which 3,140 also fell into one of the three previous categories). The mean age of the total group was 43 years (SD 7.0); 52\% were male.

Details of demographics, workplace exposure, and respiratory sickness absence characteristics for the for random all-population sample and for the study population broken down by condition/symptom group are presented in Table 1. The random all-population sample demonstrates that VGDF exposure (low or high) was present for more than one-third (38\%). Respiratory-related work absences overall were uncommon, reported by 142 (2.4\%); defined as absences of 3 days or more, this rate fell to $1.3 \%$, similar to the proportion who reported leaving a job at any point in the past owing to breathing problems. Statistically significant differences $(p<0.05)$ were present among the three condition/symptom-based categories for all of the demographic, exposure, and health outcomes variables shown in Table 1 (except age, $p=0.58$ ). Overall, those with wheeze/breathlessness manifested the highest proportion of current smokers, high VGDF exposure jobs, and second hand smoke exposure at work. Those with asthma most frequently reported chest tightness on the current job, leaving a previous job due to breathing problems, and the greatest frequency of respiratory sickness absence, whether defined as at least one day or more or greater than three days. Among all those in the condition/symptom groups, 327 (6.9\%) of 4,772 reported respiratory sickness absence.

In multiple logistic regression analysis taking into account sex, age, smoking, and study region, respiratory sickness absence among those in the stratum with asthma was significantly associated with both the asthma symptom score (OR 1.61, CI 1.42-1.82) and high exposure to 
VGDF at current work (OR 1.96, CI 1.06-3.64) (Table 2). Among those with wheeze or breathlessness and among the rhinitis stratum, high VGDF exposure was also significantly associated with respiratory sickness absence. There was no consistent relationship to respiratory sickness absence across the condition strata for the other risk factors analyzed.

Second hand smoke exposure at work manifested no statistically significant risk for increased respiratory sickness absence when added to these models (data not shown). Results from the random intercept logistic models including geographic region as a random effects variable were consistent with the main findings by the conventional logistic model in which region was treated as a fixed effect. The main findings remained the same after applying the prediction model with more than three days of respiratory sickness absence as the outcome, although the observed point estimates had larger confidence intervals (data not shown).

Additional analyses with stratification by sex generally showed similar patterns to the models without stratification (data not shown). When subjects with asthma were stratified by childhood-onset asthma vs. later onset, the association between respiratory sickness absence and work exposure to VGDF remained only among those with adult onset disease (childhoodonset OR 1.49, 95\% CI 0.64-3.48; later onset OR 2.70, 95\% CI 1.09-6.68). However, the association between respiratory sickness absence and asthma symptom score was still present in both asthma strata (childhood-onset OR 1.61, 95\% CI 1.37-1.89; later onset OR 1.61,95\% CI 1.33-1.96).

\section{Discussion}

In this analysis, respiratory sickness absence was relatively common in persons with either physician-diagnosed asthma, wheeze/breathlessness without an asthma diagnosis, or selfreported rhinitis without either of the two previous lower respiratory conditions. Of particular note, occupational exposure to VGDF was consistently associated with respiratory sickness absence regardless of which condition/symptom categorization of lower and upper respiratory morbidity was analyzed. This was true taking potential confounders into account, which varied significantly among these three groups. 
To date, few studies have attempted to demonstrate the association between respiratory tract conditions or symptoms and respiratory sickness absence. Post and co-workers showed that subjects with one or more respiratory symptoms had significantly higher odds (OR 4.4) of having respiratory sickness absence [Post et al., 1994]. They classified respiratory symptoms into nine different categories, including asthma-like symptoms and chronic bronchitis-like symptoms, but the analyses for predictors of respiratory sickness absence were carried out without taking these categories into consideration. Another study by Alexopoulos and Burdorf [2001], noted previously, in addition to identifying increased risk among blue collar workers showed that those with asthma complaints were at increased risk for sickness absence due to asthma-like symptoms, with a relative risk of 3.96 (95\% CI 2.0-7.9). In that study, however, complaints about chronic obstructive pulmonary disease (COPD) or a combination of several respiratory symptoms were not associated with sickness absence due to respiratory disorders.

A cohort study of Swedish pulp mill workers showed that gassing episodes predicted having to change jobs due to respiratory problems even taking into account asthma, chronic bronchitis and rhinitis [Murgia et al., 2011]. To the best of our knowledge, there are no published data on factors associated with respiratory sickness absence that separately analyze models stratified by respiratory tract condition/symptom group as we have done here. Moreover, we were also able to test this model in a random all-population sample (by design including some of each of these groups, as this best reflects a "real-world" mix of the healthy and the ill).

The data for the present study were drawn from a large multinational follow-up survey among adults. The results regarding increased respiratory sickness absence among those with asthma are in good agreement with previous findings [Alexopoulos and Burdorf 2001; Blanc et al., 1999]. In the present study, asthma symptom scores were strongly associated with respiratory sickness absence in asthmatic working adults. It has been previously shown that moderate or severe baseline severity of asthma carried an increased odds of work disability among asthmatic patients (OR 1.4, CI 1.03-1.84) [Gonzalez Barcala et al., 2011]. The association we observed between VGDF exposure and respiratory sickness absence is in good agreement with previous studies reporting that VGDF exposure at work is a predictor of respiratory work disability measured in other ways, including analyses of the baseline ECRHS cohort [Blanc et al., 1999; Toren et al., 2009]. 
In this study, we defined respiratory sickness absence in our primary analyses as at least one day of sickness absence due to asthma or wheeze/breathlessness during the last 12 months. A one day cut-off for sickness absence can be problematic and we thus performed additional analyses with defined respiratory sickness absence as more than three days of respiratory sickness absences. The main findings remained similar, albeit with wider confidence intervals, reflecting relatively limited power to study respiratory sickness absence so defined even in a relatively large study group. Vahtera and co-authors mentioned that short-term general sickness absences up to 3 days was a relatively weak predictor of mortality compared to more than 3 days of sickness absence [Vahtera et al., 2004]. Even though it is unclear whether the same effect would be operative in regards to respiratory-specific absences, the findings with our one-day respiratory sickness absence measure should not be interpreted to imply later mortality risk.

Analysis stratified by childhood onset and adult asthma showed that work exposure to VGDF was no longer a significant predictor of increased respiratory sickness absence in those with childhood-onset asthma, although the association with asthma symptom score was similar in both strata. Those with childhood-onset asthma may avoid going into jobs with VGDF exposure. A previous analysis of the ECHRS found that adults with asthma onset prior to entering the workforce are less likely to have a job with high or low exposure to dusts, gases, and fumes [Olivieri et al., 2010]. This self selection phenomenon was also observed in the recent prospective study and there was a stronger selection at hire among those with more severe or more symptomatic asthma in childhood [Dumas et al., 2010]. Thus, our findings should be generalized with caution depending on the mix of childhood- vs. adult-onset asthma in any given population.

Our analysis also has potential methodological limitations. Since the study population was drawn from several different study regions, there may be differences in personal and societal approaches to sickness absence due to respiratory tract conditions or symptoms, for example, greater likelihood of staying at work even when unwell in some populations than others. Taking study region into account (either a fixed or random effect variable) did not alter the associations we observed, but we did not have national or even regional data by the study site level for economic status measures such as Gross Domestic Product or local unemployment 
figures. A related potential confounder is the association between VGDF and socioeconomic status. If it is presumed that greater exposures also reflect lower wages, this unmeasured covariate of socioeconomic status that might be the "true" risk factor for respiratory sickness absence. The causal pathway we hypothesized is that VGDF exposure leads to respiratory sickness absence. Nonetheless, we cannot exclude the possibility that lower socioeconomic status is linked both to poor working conditions and other exposures, for example, poor housing conditions increasing the risk of respiratory infection and thus respiratory sickness absence.

Questionnaire responses may introduce measurement imprecision. Self-reported health data are commonly used in epidemiological studies such as the international standard questions in the ECHRS regarding asthma, wheeze, breathlessness, and rhinitis. Self-reported physiciandiagnosed asthma has high specificity, but low sensitivity [Toren et al., 1993], which makes it a suitable epidemiological measure. Retrospective data can contribute to under or overestimation owing to non-systematic recall error. Most of the response options in our study were a simple choice of yes or no. Questions also elicited symptoms/exposure in the last 12 months, which is a relatively short time period. We therefore believe that recall errors, which would bias to the null, would not explain the associations we observed. Potential systematic recall bias would be relevant had we relied on subject report of job exposure, but we assigned VGDF exposure likelihood on the basis of a job exposure matrix. Nevertheless, we cannot exclude the possibility that symptom reporting might have been affected by recall effects associated with diagnostic category or other unmeasured covariates.

\section{Conclusion}

Occupational exposure to vapors, gas, dust, or fume may affect respiratory work ability among workers who are currently employed and have not yet left work altogether. Reducing airborne exposure in the workplace may help in reducing absence from work due to respiratory problems. 
Acknowledgements: List of Principal Investigators and Senior Scientific Team. Australia: Melbourne: M. Abramson, R. Woods, E.H. Walters, F. Thien, G Benke. Belgium: South Antwerp \& Antwerp City: P Vermeire, J Weyler, M Van Sprundel, V Nelen. Estonia: Tartu: R Jogi, A Soon. France: Paris: F Neukirch, B Leynaert, R Liard, M Zureik; Grenoble: I Pin, J Ferran-Quentin. Germany: Erfurt: J Heinrich, M Wjst, C Frye, I Meyer. Iceland: Thorarinn Gislason. Italy: Turin: M. Bugiani, P. Piccioni, A. Carosso, W. Arossa, E. Caria, G. Castiglioni, E. Migliore, C. Romano, D. Fabbro, G. Ciccone, C. Magnani, P. Dalmasso, R. Bono, G. Gigli, A. Giraudo, M.C. Brussino, C. Bucca, G. Rolla; Verona: R de Marco, G Verlato, E Zanolin, S Accordini, A Poli, V Lo Cascio, M Ferrari; Pavia: A Marinoni, S Villani, M Ponzio, F Frigerio, M Comelli, M Grassi, I Cerveri, A Corsico. The Netherlands: J Schouten. Norway: Bergen: A. Gulsvik, E. Omenaas, C. Svanes, B. Laerum. Spain: Barcelona: JM Antó, J Sunyer, M Kogevinas, JP Zock, X Basagana, A Jaen, F Burgos; Huelva: J Maldonado, A Pereira, JL Sanchez; Albacete: J Martinez-Moratalla Rovira, E Almar; Galdakao: N Muniozguren, I Urritia; Oviedo: F Payo. Sweden: Uppsala: C Janson, G Boman, D Norback, M Gunnbjornsdottir; Goteborg: K Toren, L Lillienberg, A Dahlman-Höglund; Umeå: E Norrman, M Soderberg, K Franklin, B Lundback, B Forsberg, L Nystrom. Switzerland: Basel: N Künzli, B Dibbert, M Hazenkamp, M Brutsche, U Ackermann-Liebrich. United Kingdom: P Burney, S Chinn, D Jarvis; Norwich: D Jarvis, B Harrison; Ipswich: D Jarvis, R Hall, D Seaton. USA: Portland: M Osborne, S Buist, W Vollmer, L Johnson. The contents of this publication are solely the responsibility of the authors and do not necessarily represent the official views of the NIH, the European Commission Quality of Life Programme or the EU Framework Programme for research.

Funding: Co-ordination of the occupational asthma component of ECRHS II was supported by grant 1 R01 HL62633-01 of the US National Institutes for Health, National occupational research agenda (NORA), and National Heart, Lung, and Blood Institute. Co-ordination of ECRHS II was supported by the European Commission (as part of their Quality of Life programme), and from research contract NoFOOD_CT_2004_506378, the Ga2len project, and the Global Allergy and Asthma European Network. The local ECRHS II studies included in this article were funded by the following bodies: Albacete: Fondo de Investigaciones Santarias (FIS) (grant codes: 97/0035-01, 99/0034-01, and 99/0034-02), Hospital Universitario de Albacete, Consejeria de Sanidad; Antwerp: FWO (Fund for Scientific Research)-Flanders Belgium (grant code: G.0402.00), University of Antwerp, Flemish Health Ministry; Barcelona: SEPAR, Public Health Service (grant code: R01 HL62633-01), Fondo de Investigaciones Santarias (FIS) (grant codes: 97/0035-01, 99/0034-01, and 99/0034-02), CIRIT (grant code: 1999SGR 00241), Red Respira ISCII; Basel: Swiss National Science Foundation, Swiss Federal Office for Education \& Science, Swiss National Accident Insurance Fund (SUVA), USC NIEHS Center (grant code: 5P30 ES07048); Bergen: Norwegian Research Council, Norwegian Asthma \& Allergy Association (NAAF), Glaxo Wellcome AS, Norway Research Fund; Erfurt: GSF-National Research Centre for Environment \& Health, Deutsche Forschungsgemeinschaft (DFG) (grant code: FR 1526/1-1); Galdakao: Basque Health Dept; Goteborg: Swedish Heart Lung Foundation, Swedish Council for Working Life and Social Research (FAS), Swedish Cancer \& Allergy Foundation; Grenoble: Programme Hospitalier de Recherche Clinique-DRC de Grenoble 2000 no. 2610, Ministry of Health, Direction de la Recherche Clinique, Ministere de l'Emploi et de la Solidarite, Direction Generale de la Sante, CHU de Grenoble, Comite des Maladies Respiratoires de l'Isere; Hamburg: GSF-National Research Centre for Environment \& Health, Deutsche Forschungsgemeinschaft (DFG) (grant code MA 711/4-1); Ipswich and Norwich: Asthma UK (formerly known as National Asthma Campaign); Huelva: Fondo de Investigaciones Santarias (FIS) (grant codes: 97/0035-01, 99/0034-01, and 99/0034-02); Melbourne: National Health and Medical Research Council of Australia; Oviedo: Fondo de Investigaciones Santarias (FIS) (grant codes: 97/0035-01, 99/0034-01, and 99/0034-02); Paris: Ministere de l'Emploi et de la Solidarite, Direction Generale de la Sante, UCB-Pharma (France), Aventis (France), Glaxo France, Programme Hospitalier de Recherche Clinique-DRC de Grenoble 2000 no. 2610, Ministry of Health, Direction de la Recherche Clinique, CHU de Grenoble; Pavia: Glaxo-SmithKline Italy, Italian Ministry of University and Scientific and Technological Research (MURST), Local University Funding for Research 1998 \& 1999 (Pavia, Italy); Tartu: Estonian Science Foundation; Turin: ASL 4 Regione Piemonte (Italy), AO CTO/ICORMA Regione Piemonte 
(Italy), Italian Ministry of University and Scientific and Technological Research (MURST), GlaxoSmithKline Italy; Umeå: Swedish Heart Lung Foundation, Swedish Foundation for Health Care Sciences \& Allergy Research, Swedish Asthma \& Allergy Foundation, Swedish Cancer \& Allergy Foundation; Uppsala: Swedish Heart Lung Foundation, Swedish Foundation for Health Care Sciences \& Allergy Research, Swedish Asthma \& Allergy Foundation, Swedish Cancer \& Allergy Foundation; Verona: University of Verona, Italian Ministry of University and Scientific and Technological Research (MURST), Glaxo-SmithKline Italy; United States: Department of Health, Education and Welfare Public Health Service (grant code: \#2 S07RR05521-28). 
Figure 1. Flow diagram illustrating the study population.

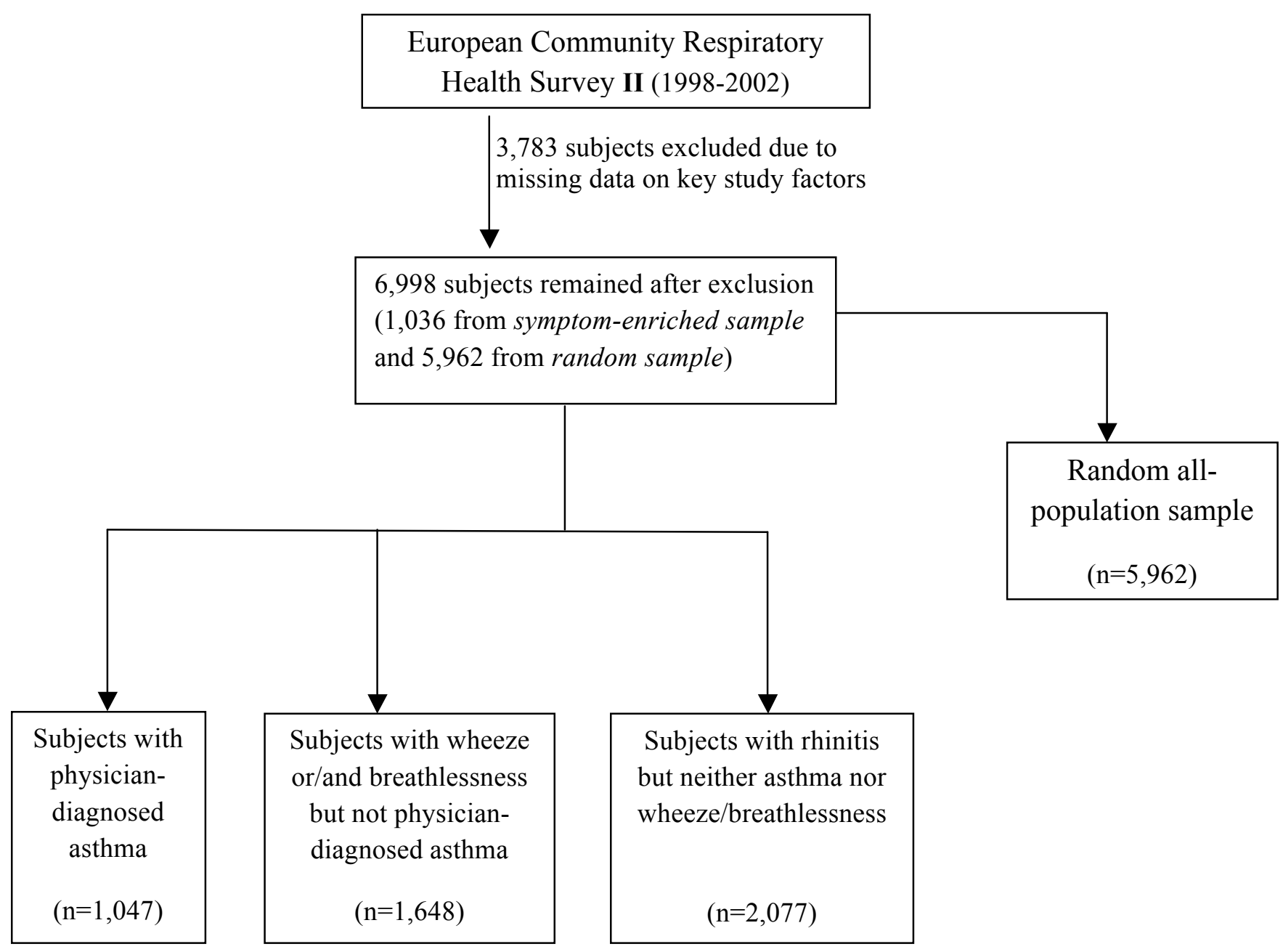




\begin{tabular}{|c|c|c|c|c|}
\hline \multirow{3}{*}{ Study participant characteristic } & \multirow{2}{*}{$\begin{array}{l}\text { Random } \\
\text { all-population sample* } \\
(\mathrm{n}=5,962)\end{array}$} & \multicolumn{3}{|c|}{$\begin{array}{l}\text { Respiratory condition/symptom groups } \\
\qquad(\mathrm{n}=4,772)\end{array}$} \\
\hline & & $\begin{array}{c}\text { Asthma } \\
(\mathrm{n}=1,047)\end{array}$ & $\begin{array}{c}\text { Wheeze/ } \\
\text { breathlessness }^{\dagger} \\
(n=1,648)\end{array}$ & $\begin{array}{l}\text { Rhinitis } \\
(\mathrm{n}=2,077)\end{array}$ \\
\hline & $\mathrm{N}(\%)$ & $\mathrm{N}(\%)$ & $\mathrm{N}(\%)$ & $\mathrm{N}(\%)$ \\
\hline Male sex & $3,133(52.6)$ & $494(47.2)$ & $866(52.6)$ & $1,009(48.6)$ \\
\hline Mean age in years (standard deviation) & $43.0(7.0)$ & $42.3(7.1)$ & $43.0(7.0)$ & $42.4(7.0)$ \\
\hline \multicolumn{5}{|l|}{ Smoking status } \\
\hline Never smoker & $2,696(45.2)$ & $532(50.8)$ & $551(33.4)$ & $1,053(50.7)$ \\
\hline Ex-smoker & $1,623(27.2)$ & $269(25.7)$ & $371(22.5)$ & $589(28.4)$ \\
\hline Current smoker & $1,643(27.6)$ & $246(23.5)$ & $726(44.1)$ & $435(20.9)$ \\
\hline \multicolumn{5}{|l|}{ Current work exposure to VGDF ${ }^{\S}$} \\
\hline None & $3,723(62.5)$ & $651(62.2)$ & $983(59.7)$ & $1,343(64.7)$ \\
\hline Low & $1,614(27.1)$ & $304(29.0)$ & $465(28.2)$ & $561(27.0)$ \\
\hline High & $625(10.5)$ & $92(8.8)$ & $200(12.1)$ & $173(8.3)$ \\
\hline Second hand smoke exposure at work & $1,015(17.1)$ & $148(14.3)$ & $412(25.0)$ & $262(12.7)$ \\
\hline Current work resulting in chest tightness or wheeze & $266(4.9)$ & $181(20.6)$ & $155(10.4)$ & $178(9.6)$ \\
\hline Leaving any job due to breathing problems & $62(1.1)$ & $42(4.8)$ & $34(2.3)$ & $39(2.1)$ \\
\hline \multicolumn{5}{|l|}{ Respiratory sickness absence, the last 12 months" } \\
\hline Mean day (min-max) & $0.3(0-350)$ & $1.7(0-270)$ & $0.6(0-350)$ & $0.7(0-270)$ \\
\hline Respiratory sickness absence ( $\geq 1$ day) & $142(2.4)$ & $139(13.3)$ & $63(3.8)$ & $125(6.0)$ \\
\hline More than three days of respiratory sickness absence & $80(1.3)$ & $95(9.1)$ & $40(2.4)$ & $77(3.7)$ \\
\hline
\end{tabular}

More than three days of respiratory sickness absence $80(1.3)$

ECRHS $=$ European Community Respiratory Health Survey.

*The random all-population sample includes 3140 persons who also fell into one of the three condition/symptom groups (see Methods).

${ }^{\dagger}$ Subjects reporting physician diagnosed asthma were excluded from the wheeze/breathlessness category.

ثSubjects with physician-diagnosed asthma or with wheeze/breathlessness were excluded from the rhinitis category.

${ }^{\S}$ VGDF = vapor, gas, dust or fumes; exposure likelihood (none, low, or high) assigned based on a job exposure matrix.

"Self-reported sick leave attributed to asthma, shortness of breath, or wheezing 
Table 2. Association of respiratory sickness absence ( $\geq 1$ day) with several predictors among current workers and within subgroups*

\begin{tabular}{|c|c|c|c|c|}
\hline & Random all & & Wheeze or & \\
\hline Risk factors & OR $(95 \% \mathrm{CI})$ & OR $(95 \% \mathrm{CI})$ & OR $(95 \% \mathrm{CI})$ & OR $(95 \% \mathrm{CI})$ \\
\hline Female sex & $1.40(0.99-1.98)$ & $1.44(0.96-2.15)$ & $2.07(1.18-3.61)$ & $1.40(0.96-2.06)$ \\
\hline Ever smoking $^{\dagger}$ & $1.22(0.87-1.72)$ & $1.03(0.71-1.51)$ & $0.80(0.47-1.35)$ & $1.06(0.73-1.53)$ \\
\hline \multicolumn{5}{|l|}{ VGDF exposure } \\
\hline None (reference) & 1 & 1 & 1 & 1 \\
\hline Asthma symptom score ${ }^{\dagger \dagger}$ & $\mathrm{NA}$ & $1.61(1.42-1.82)$ & NA & NA \\
\hline
\end{tabular}

$\mathrm{NA}=$ Not applicable; $\mathrm{VGDF}=$ vapors, gas, dust or fumes. $\mathrm{OR}=$ odds ratio. $\mathrm{CI}=$ confidence interval.

*Multiple logistic regression models were applied. Each model was separately tested for each respiratory category, with mutual adjustment for all of the other predictor variables shown, as well as study region (see Methods).

${ }^{\dagger}$ Referent category $=$ never smoker.

${ }^{\dagger}$ Calculated by 5-point scale of symptom score only for subjects with asthma. OR is expressed per point change. 


\section{References}

Alexopoulos EC, Burdorf A. 2001. Prognostic factors for respiratory sickness absence and return to work among blue collar workers and office personnel. Occup Environ Med 58: 246-252.

Barmby TA, Ercolani MG, Treble JG. 2002. Sickness absence: An international comparison. Economic Journal 112.

Blanc PD, Burney P, Janson C, Toren K. 2003. The prevalence and predictors of respiratory-related work limitation and occupational disability in an international study. Chest 124: 1153-1159.

Blanc PD, Ellbjar S, Janson C, Norback D, Norrman E, Plaschke P, Toren K. 1999. Asthma-related work disability in Sweden. The impact of workplace exposures. Am J Respir Crit Care Med 160: 2028-2033.

Bedada GB, Heinrich J, Gotschi T, Downs SH, Forsberg B, Jarvis D, Luczynska C, Soon A, Sunyer J, Toren K, Kunzli N. 2007. Urban background particulate matter and allergic sensitization in adults of ECRHS II. Int J Hyg Environ Health 210: 691-700.

Burney PG, Luczynska C, Chinn S, Jarvis D. 1994. The European Community Respiratory Health Survey. Eur Respir J 7: 954-960.

Cody RP, Smith JK. 2005. Applied statistics and the SAS programming language. Upper Saddle River, New Jersey: Pearson Prentice Hall. pp. 300.

Dumas O, Smit LA, Pin I, Kromhout H, Siroux V, Nadif R, Vermeulen R, Heederik D, Hery M, Choudat D, Kauffmann F, Le Moual N. 2010 Do young adults with childhood asthma avoid occupational exposures at first hire? Eur Respir J. 2011;37:1043-9.

European Respiratory Health Survey II Steering Committee. 2002. The European Community Respiratory Health Survey II. Eur Respir J 20: 1071-1079.

Gonzalez Barcala FJ, La Fuente-Cid RD, Alvarez-Gil R, Tafalla M, Nuevo J, Caamano-Isorna F. 2011. Factors associated with a higher prevalence of work disability among asthmatic patients. J Asthma 48: 194-199.

International Labour Organization. 1991. International standard classification of occupations. International Labour Organization.

Koopmans PC, Roelen CA, Groothoff JW. Frequent and long-term asbsence as a risk factor for work diability and job termination among employees in the private sector. Occup Environ Med 2008; 65:494-499.

Laaksonen M, Mastekaasa A, Martikainen P, Rahkonen O, Piha K, Lahelma E. 2010. Gender differences in sickness absence - the contribution of occupation and workplace. Scand J Work Environ Health 36: 394-403.

Matheson MC, Benke G, Raven J, Sim MR, Kromhout H, Vermeulen R, Johns DP, Walters EH, Abramson MJ. 2005. Biological dust exposure in the workplace is a risk factor for chronic obstructive pulmonary disease. Thorax 60: 645-651.

Murgia N, Toren K, Kim JL, Andersson E. 2011. Risk factors for respiratory work disability in a cohort of pulp mill workers exposed to irritant gases. BMC Public Health 11: 689. 
Olivieri M, Mirabelli MC, Plana E, Radon K, Anto JM, Bakke P, Benke G, D'Errico A, Henneberger P, Kromhout H, Norback D, Toren K, van Sprundel M, Villani S, Wieslander G, Zock JP, Kogevinas M. 2010. Healthy hire effect, job selection and inhalation exposure among young adults with asthma. Eur Respir J 36: 517-523.

Post WK, Burdorf A, Bruggeling TG. 1994. Relations between respiratory symptoms and sickness among workers in the animal feed industry. Occup Environ Med 51: 440-446.

Sunyer J, Pekkanen J, Garcia-Esteban R, Svanes C, Kunzli N, Janson C, de Marco R, Anto JM, Burney P. 2007. Asthma score: predictive ability and risk factors. Allergy 62: 142-148.

Sunyer J, Zock JP, Kromhout H, Garcia-Esteban R, Radon K, Jarvis D, Toren K, Kunzli N, Norback D, d'Errico A, Urrutia I, Payo F, Olivieri M, Villani S, Van Sprundel M, Anto JM, Kogevinas M. 2005. Lung function decline, chronic bronchitis, and occupational exposures in young adults. Am J Respir Crit Care Med 172: 1139-1145.

Toren K, Brisman J, Jarvholm B. 1993. Asthma and asthma-like symptoms in adults assessed by questionnaires. A literature review. Chest 104: 600-608.

Toren K, Zock JP, Kogevinas M, Plana E, Sunyer J, Radon K, Jarvis D, Kromhout H, d'Errico A, Payo F, Anto JM, Blanc PD. 2009. An international prospective general population-based study of respiratory work disability. Thorax 64: 339-344.

Vahtera J, Pentti J, Kivimaki M. 2004. Sickness absence as a predictor of mortality among male and female employees. J Epidemiol Community Health 58: 321-326.

Vandenplas O, Toren K, Blanc PD. 2003. Health and socioeconomic impact of work-related asthma. Eur Respir J 22: 689-697. 